\title{
Is Cues of Contagious Diseases
} in Advertising a Friend or Foe?

Dr (Mrs.) Achini Ranaweera, a Senior lecturer from the Department of Textile and Apparel Engineering, Faculty of Engineering and Dr (Mrs.) Amali Wijekoon, a Senior lecturer from the Department of Management Technology, Faculty of Business in collaboration with two international researchers from Australia and the UK are all geared up to examine if cues of contagious disease in advertisements can influence consumption behaviour by eliciting negative emotions such as anxiety, disgust, and fear.

We are all well aware of how the Covid-19 pandemic has caused devastating economic and social disruptions globally. The pandemic caused serious health, economic, social, business, travel, education, and workplace challenges to almost all the consumers across the world. From a marketing perspective, these challenges have led to dramatic changes in how consumers behave [1], [2]. In fact, Covid-19 pandemic represents one of the most significant environmental changes in modern marketing history [3]. Thus, understanding the changes in consumer behavior is critically important to marketers going forward. Given this background, this proposed research seeks to examine the impact of Covid-19 on consumer behavior, in particular consumers' impulsive buying behavior, hoarding behavior, and consumers' intention to recycle. We further predict that consumer's negative emotions evoked by both visual and written cues of contagious disease in advertisements will act as a mediator on this relationship. We further predict that individual differences in perceived vulnerability to infectious disease will moderate the contagious disease cue effect on the predicted relationships.
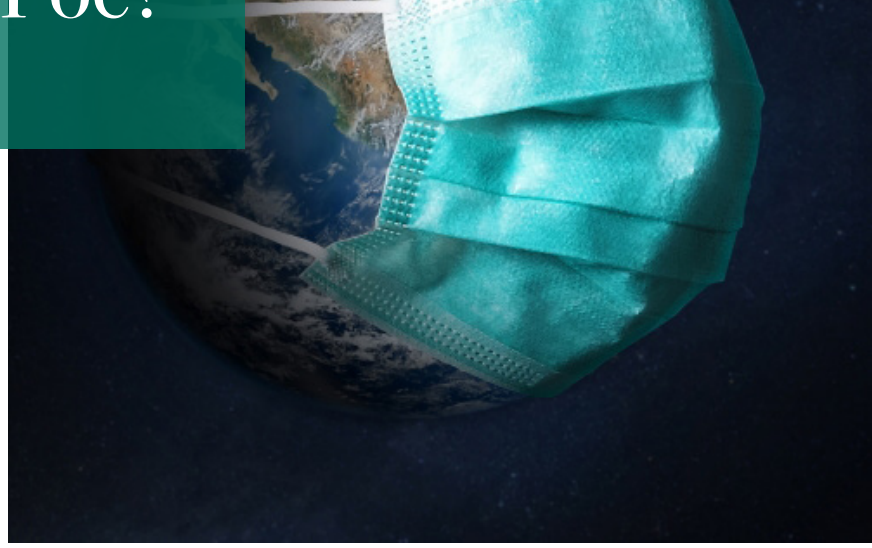

Image: Council of Europe (2021)

This research will adopt an experimental research approach, thereby designed three marketing experiments, which will also be conducted using a large sample of real- life consumer samples from USA. This research aims to contribute to the ongoing discussion on how Covid-19 pandemic influences CSR, market, and consumer behaviour.

\section{References}

[1]. Donthu, N., \& Gustafsson, A. (2020). Effects of COVID-19 on business and research. Journal of Business Research, 117, 284-289.

[2]. Kirk, C. P., \& Rifkin, L. S. (2020). I'll trade you diamonds for toilet paper: Consumer reacting, coping and adapting behaviors in the COVID-19 pandemic. Journal of Business Research

[3].He, H., \& Harris, L. (2020). The impact of Covid-19 pandemic on corporate social responsibility and marketing philosophy. Journal of Business Research, 116, 176-182.

Article by

Achini Ranaweera', Amali Wijekoon²

'Department of Textile \& Apparel Engineering,

Faculty of Engineering, University of Moratuwa, Sri Lanka.

2Department of Management of Technology, Faculty of Business, University of Moratuwa, Sri Lanka. 